\title{
Assessment of informal settlement and associated factors as a public health issue in Bahir Dar city, North West Ethiopia; a community based case control study
}

\author{
Getalem Aychew Beyene*, Yenew Amsal Dessie \\ Mahibere Hiwot for Social Development, Bahir Dar, Ethiopia \\ Email address: \\ gechlove44@gmail.com (G. A. Beyene), yenew_2006@yahoo.com (Y. A. Dessie)
}

To cite this article:

Getalem Aychew Beyene, Yenew Amsal Dessie. Assessment of Informal Settlement and Associated Factors as a Public Health Issue in Bahir Dar City, North West Ethiopia; a Community Based Case Control Study. Science Journal of Public Health.

Vol. 2, No. 4, 2014, pp. 323-329. doi: 10.11648/j.sjph.20140204.23

\begin{abstract}
Background: Informal settlements are housing units that are constructed without compliance of current planning and building regulations. This kind of settlement has become a common practice in recent years in Bahir Dar. Inhabitants who live in these unplanned housing units are often exposed to health risks associated with environmental problems. The objective of this study was to assess the existence of illnesses by infectious diseases associated to informal settlements and exploring associated risk factors in Bahir Dar city. Methods: unmatched case-control quantitative study complemented with qualitative exploration was conducted in Bahir Dar city, from 1 June-31 September 2011. A total of 555 households (185 informal and 370 formal households) were selected by systematic random sampling technique proportional to the number of households in respective sub cities. Pre tested semi structured questionnaire and observation checklist were used to collect the data. Data were coded, entered and cleaned using epidemiological information version 3.3.2, and analyzed by SPSS version 15. Results: As a result, existence of illness by infectious diseases among informally established housing units was found to be $39.5 \%$ compared to $10.8 \%$ among formally established housing units. The likelihood of establishing informal houses is associated with socio-economic and demographic factors such as respondents' age [AOR=2.78, 95\% CI; 1.34-5.68], education [AOR=9.28, 95\%CI: 3.24-26.57], occupation [AOR=2.47, 95\%CI: $1.08-5.66]$, and average monthly income [AOR=2.58, 95\%CI: 1.57-4.23]. Conclusion: The prevalence of illness among informally established housing units were more than formally established housing units. Diarrheal diseases, malaria, typhoid and typhus were the most infectious diseases found to be prevalent in informally established housing units, so that expansions of income generating activities and taking corrective measures to minimize the adverse effects of environmental problems on health status of the people are recommended.
\end{abstract}

Keywords: Informal Settlement, Public Health Issue, Bahir Dar City

\section{Introduction}

Informal settlements are defined as residential housing units built on planned and unplanned areas without formal approval from the concerned body [1]. In most cities of the world, slums, by definition, are informal and illegal settlements [2].

The underlying reasons why informal settlements exist are poverty, population growth, urbanization, land scarcity and environmental hazards. In informal settlements, most of the houses have been built by the families who occupy them. Infrastructure and services are lacking, and the house materials are of a temporary nature [3].
Informal settlements are associated with developing countries and characterized by severe overcrowding; deficient access to water and sanitation facilities. This lack of proper drainage and waste removal results pollution of water, air and soil. The existence of overcrowding can contribute to stress, violence and other social problems. The houses of the inhabitants are constructed with simple materials such as plastic sheets and other low quality materials without adequate ventilation. These lacks of facilities play a major role in spread of diseases [4].

Bahir Dar is one of the cities of Ethiopia where significant number of informally established housing units are observed. The number of informally established housing units was 
3504 in 1994. This figure rose to 4823 in 1999/2000 with an increase of 38 percent. In 2005, the number of illegal and/or informal houses was 5000 in the city and its vicinity [5].

There is limited information about the spectrum and burden of disease morbidity in informal settlements of the world. This lack of such information hinders fair distribution of health care resources and provision of appropriate disease prevention services. The formal health sectors address dwellers of informal settlement only when they end up with the complications of their chronic illness. They treat these complications at a tremendous cost to their health care resources. Therefore, concerted effort is urgently needed to assess health burden and determinants of disease morbidity among residents of informal settlement at the community level [2].

Therefore, the aim of this study is to assess situation of informal settlement and exploring associated risk factors in Bahir Dar city, North West Ethiopia. The authors hypothesized that people who live in informal settlements are affected by various factors than those who live in formal settlements.

The causes and adverse effects of informal settlement are rarely researched in the area of public health. In order to fill this gap this research is conducted. The findings of this study will provide information to concerned bodies that have an intention to be engaged in urban planning, health resource allocation, infrastructural development and placement.

\section{Methods and Materials}

Unmatched case control, quantitative supplemented by qualitative study design was employed in Bahir Dar city, North West Ethiopia from 1 June - 31 September, 2011. Bahir Dar is the capital of Amhara National Regional State far from $567 \mathrm{~km}$ away from Addis Ababa and for administrative purpose classified in to 9 urban Sub city and 4 satellite kebelles. The source population includes all 28,676 registered houses in Bahir Dar City. Systematic random sampling technique proportional to number of households in respective sub cities were used to select the study population from the source population. The sample size include 555 housing units of which 185 were informally established and 370 were formally established housing units who full fill the inclusion criteria. Housing units that are headed by children below eighteen years of age, mentally sick people, respondents with hearing impairments or people who live in houses constructed for less than six months were excluded from the study. The sampling procedure is presented as follows

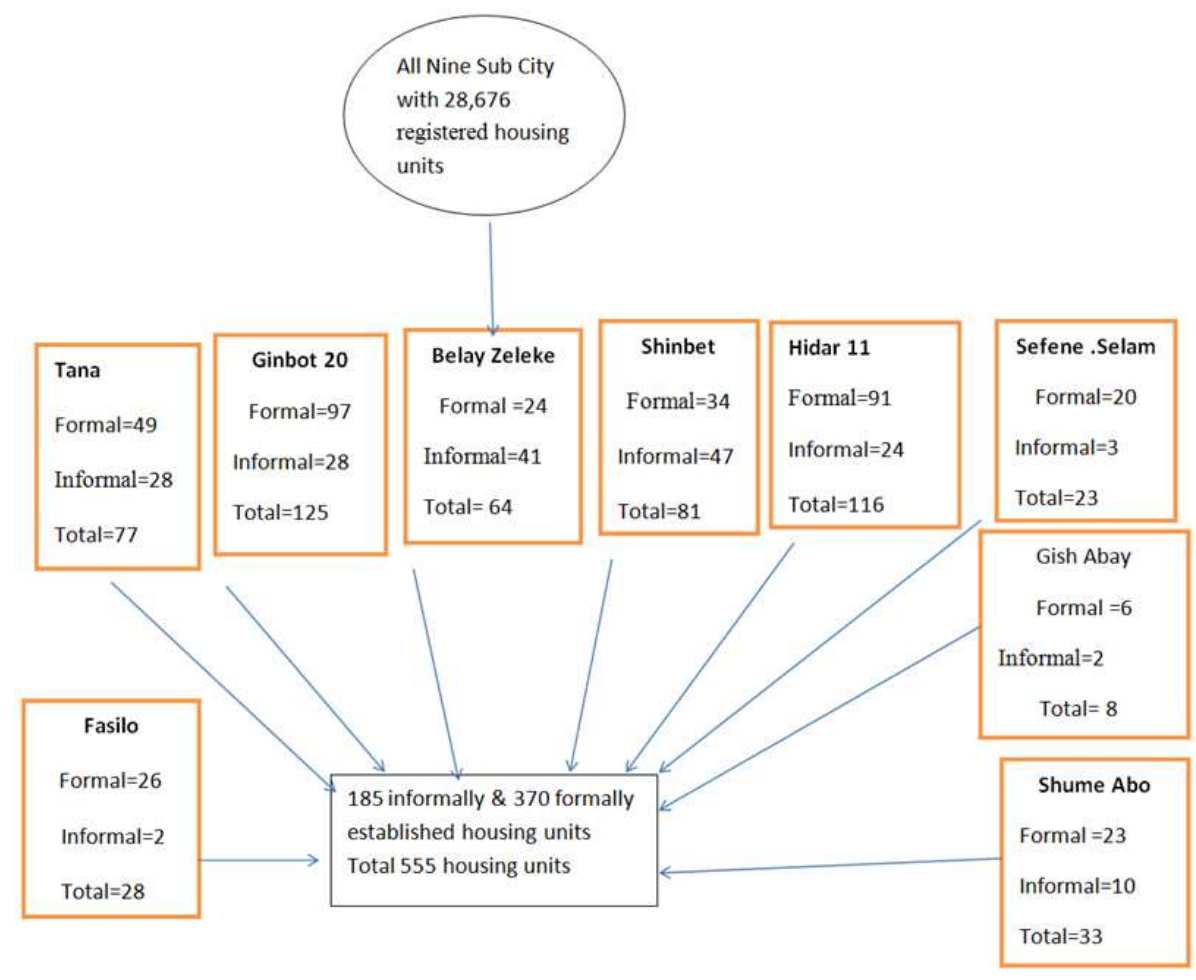

Fig. 1. Schematic presentation of sampling procedure

Data were collected using semi structured Amharic (the local language) questionnaire through face to face interview. Direct observation of physical and social environments of both settlements by using observation checklist were conducted to collect qualitative data. One day training has been given for eight data collectors and two supervisors on the objective of the study, techniques how to approach respondents, techniques of face to face interview and how to keep confidentiality.

\subsection{Operational Definition}

Formal Settlement:-. Housing units constructed in 
planned area in compliance with building code of the municipality.

Informal Settlement: -Housing units constructed in planned/unplanned area without compliance with building code of the municipality.

Sufficient living area/Absence of overcrowding:- Fewer than 3 persons live per room or a minimum of four square meter [6].

Ventilation:- is the existence of at least one window per room for the circulation of the air in the room

Improved sanitation facilities: Availability, accessibility and affordability of safe solid or liquid waste disposal facilities such as connection to public sewers, septic systems, pour-flush latrines, simple pit latrines and ventilated improved pit latrines [7].

Improved access to water: defined as availability, accessibility and affordability of at least 20 liters of water per person per day from water sources include piped in to dwelling piped in to compound, tube or borehole, public, protected dug wells, protected springs, and rainwater collections $[7,8]$.

\subsection{Data Quality, Management and Analysis}

Pre- test was done in a similar setting out of the study area. Internal consistency of the questionnaire were measured by reliability analysis by calculating chronbach's alpha. Data was checked for accuracy, completeness and consistency of responses manually by supervisors and principal investigators every day. Data were coded, entered and cleaned using epidemiological information (EPINFO) version 3.3.2, and exported to statistical package for social sciences (SPSS) version 15 for analysis. Descriptive statistics was used to summarize the data. The degree of association between dependent and predictor variables was assessed using crude odds ratio (COR). Adjusted odds ratio (AOR) for each independent variable was calculated using backward stepwise binary logistic regression analysis model to control potential confounding variables. Qualitative data was summarized manually and discussed along with quantitative finding to validate quantitative data. P value less than 0.05 was considered statistically significant.

Table 1. Socio demographic characteristics of housing units, 1 June - 31 September 2011, Bahir Dar City, NW Ethiopia.

\begin{tabular}{|c|c|c|c|c|c|}
\hline Variables & Cases $n=185(\%)$ & Controls $\mathrm{n}=357(\%)$ & Total $n=555(\%)$ & Chi-square & P-Value \\
\hline \multicolumn{6}{|l|}{ Sex } \\
\hline Male & $121(65.4)$ & $275(74.3)$ & $396(71.4)$ & 4.8 & $0.02 *$ \\
\hline Female & $64(34.6)$ & $95(25.7)$ & $159(28.6)$ & & \\
\hline \multicolumn{6}{|l|}{ Age } \\
\hline$<30$ & $32(17.3)$ & $45(12.2$ & 77 (13.9) & & \\
\hline $30-39$ & $48(25.9)$ & $67(18.1)$ & $115(20.7)$ & 12.82 & $0.012 *$ \\
\hline $40-49$ & $43(23.2)$ & $107(28.9)$ & $150(27)$ & & \\
\hline $50-59$ & $24(13)$ & $81(21.9)$ & $105(18.9)$ & & \\
\hline $60+$ & $38(20.5)$ & $70(18.9)$ & $108(19.5)$ & & \\
\hline \multicolumn{6}{|l|}{ Place of Birth } \\
\hline Bahir Dar & $60(32.4)$ & $138(37.3)$ & $198(35.7)$ & & \\
\hline Out of Bahir Dar & $125(67.6)$ & $232(62.7)$ & $357(64.3)$ & 1.27 & 0.25 \\
\hline \multicolumn{6}{|l|}{ Educational status } \\
\hline Illiterate & $55(29.7)$ & $50(13.5)$ & $105(18.9)$ & & \\
\hline Read and Write & $31(16.8)$ & $45(12.2)$ & $76(13.7)$ & & \\
\hline Grade 1-6 & $43(23.2)$ & $41(11.1)$ & $84(15.4)$ & 66.68 & $0.00 * *$ \\
\hline Grade $7-8$ & $11(5.9)$ & $46(12.4)$ & $57(10.3)$ & & \\
\hline Grade $9-12$ & $36(19.5)$ & $92(24.9)$ & $128(23.1)$ & & \\
\hline Certificate and above & $9(4.9)$ & $96(25.9)$ & $105(18.9)$ & & \\
\hline \multicolumn{6}{|l|}{ Occupational status } \\
\hline Government Employee & $22(11.9)$ & $101(27.3)$ & $123(22.2)$ & & \\
\hline House wife & $17(9.2)$ & $42(11.4)$ & $59(10.6)$ & & \\
\hline Merchant & $26(14.1)$ & $84(22.7)$ & $110(19.80)$ & 82.29 & $0.00 * *$ \\
\hline Daily Laborer & $66(35.7)$ & $27(7.3)$ & $93(16.8)$ & & \\
\hline Farmer & $8(4.3)$ & $6(1.6)$ & $14(2.5)$ & & \\
\hline Others & $46(24.9)$ & $110(29.7)$ & $156(28.1)$ & & \\
\hline \multicolumn{6}{|l|}{ Religion } \\
\hline Christians & $173(93.5)$ & $323(87.3)$ & $496(89.4)$ & & \\
\hline Muslims & $12(6.5)$ & $47(12.7)$ & $59(10.6)$ & 5.2 & $0.02 *$ \\
\hline \multicolumn{6}{|l|}{ Ethnicity } \\
\hline Amhara & $182(98.4)$ & $347(93.8)$ & $529(95.3)$ & & \\
\hline Others & $3(1.6)$ & $23(6.2)$ & $26(4.7)$ & 5.83 & $0.01 *$ \\
\hline \multicolumn{6}{|l|}{ Income } \\
\hline Less than 600 Birr & $124(67)$ & $123(33.2)$ & $247(44.5)$ & $56 . .99$ & $0.004 *$ \\
\hline Greater than 600 Birr & $61(33)$ & $247(66.8)$ & $308(55.5)$ & & \\
\hline
\end{tabular}

$\mathrm{P}<0.05$ significant* $\mathrm{p}<0.001$ highly significant** 


\subsection{Ethical Consideration}

Ethical clearance obtained from University of Gondar. Permission was also obtained from Bahir Dar City Administration to communicate affiliated sub cities. Informed oral consent was obtained from the study participants after explaining the purpose and objective of the study. Participants were told that they had the right to withdraw from the study at any time during the interview. To ensure confidentiality and privacy of participants names or codes that led to identify the respondent for the third party were not recorded throughout the study.

\section{Result}

\subsection{Socio Demographic Characteristics of Respondents}

A total of selected 555 heads of housing units were interviewed. Among these study subjects, 370(controls) were formally established households where as 185 study subjects (cases) were informally established housing units. About $65.4 \%$ of cases and $74.3 \%$ of controls were headed by males. A place of birth for $67.6 \%$ of cases is out of Bahir Dar compared to $62.7 \%$ of controls. Regarding educational status about $29.7 \%$ of cases were illiterate compared to 13.5 controls. About $4.9 \%$ of cases and $25.9 \%$ controls have received certificate and above. Pertaining to their occupational status, $14.1 \%$ of cases and $22.7 \%$ were merchants, while $11.9 \%$ case and $27.3 \%$ controls were government employees. About $93 \%$ of cases and $87.3 \%$ of controls were Christians in their religious back ground. The majority, 98.4 cases and 93.8 controls belong to Amhara ethnic groups. The average monthly income of cases greater than Birr 600 is $33 \%$ compared to $66.8 \%$ control groups table [table 1]

\subsection{Housing Conditions}

Overcrowding is prevalent among $54.1 \%$ of cases and $20.3 \%$ controls. About 42.7 cases and 48.1 controls live in unventilated rooms. With regard to year of construction, $57.3 \%$ of informal houses and $30.8 \%$ formally established households were constructed before the year 1991.All informal houses were constructed with non-durable materials, where as $61.1 \%$ of formally established houses were built with non-durable materials. About $61.1 \%$ of cases and $10 \%$ of controls had no kitchen. About 109(96.5\%) of cases and $94.1 \%$ of controls prepare their food in open spaces in the absence of kitchen. As far as latrine facilities were concerned, $18.9 \%$ cases and 1.4 controls have no any kind of household latrine facilities. With regard to type of latrine facilities, 78.4 cases $\%$ and $45.7 \%$ controls had no improved latrine facilities.

\subsection{Waste Management Practice}

About $77.3 \%$ of cases and $57.8 \%$ of controls practice improper liquid waste management whereas $50.8 \%$ of cases and $12.7 \%$ of controls had improper dry waste management practice. Prevalence of illness with infectious diseases is investigated among $39.5 \%$ of cases and $10.8 \%$ of controls were exposed to infectious diseases mainly diarrheal diseases, malaria, typhoid, typhus other infectious diseases [table2]

Table 2. Distribution of housing units with their waste management practice, prevalence of conflict, level of satisfaction and prevalence of illness, 1 June - 31 September 2011, Bahir Dar City, NW Ethiopia.

\begin{tabular}{|c|c|c|c|c|c|}
\hline Variables & Cases $n=185(\%)$ & Controls $n=357(\%)$ & Total $n=555(\%)$ & Chi-square & P-value \\
\hline \multicolumn{6}{|c|}{ Improper Liquid waste Management } \\
\hline Yes & $143(77.3)$ & $214(57.8)$ & $357(64.3)$ & 20.35 & $0.000 * *$ \\
\hline No & $42(22.7)$ & $156(42.2)$ & $198(35.7)$ & & \\
\hline \multicolumn{6}{|c|}{ Improper dry waste Management } \\
\hline Yes & $94(50.8)$ & $47(12.7)$ & $141(25.4)$ & 94.51 & $0.00 * *$ \\
\hline No & $91(49.2)$ & $323(87.3)$ & $414(74.6)$ & & \\
\hline \multicolumn{6}{|c|}{ Prevalence of Conflict } \\
\hline Yes & $20(10.8)$ & $(1.4)$ & $25(4.5)$ & 25.66 & $0.00 * *$ \\
\hline No & $165(89.2)$ & $365(98.6)$ & $530(95.5)$ & & \\
\hline \multicolumn{6}{|c|}{ Level of satisfaction in their shelter } \\
\hline Yes & $141(76.2)$ & $3(0.8)$ & $144(25.9)$ & 364.90 & \\
\hline No & $44(23.8)$ & $367(99.2)$ & $411(74.1)$ & & $0.00 * *$ \\
\hline \multicolumn{6}{|c|}{ Prevalence of Illness } \\
\hline Yes & $73(39.5)$ & $40(10.8)$ & $113(20.4)$ & 62.43 & \\
\hline No & $112(60.5)$ & $330(89.2)$ & $442(79.6)$ & & $0.00 * *$ \\
\hline
\end{tabular}

$\mathrm{P}<0.05$ significant $\mathrm{P}<0.001$ highly significant**

\subsection{Determinants of Settlement}

Respondent's educational status showed significant difference with form of settlement. Respondents who are illiterate, able to read and write, 1-6 and 9-12 grades were nine, five and half, eight and three and half times more likely to establish informal houses than whose educational status are certificate and above, respectively $[\mathrm{AOR}=9.28,95 \% \mathrm{CI}$ : 3.24-26.57], [AOR=5.58, 95\%CI: $1.95-15.96]$, [AOR=8.02, 95\%CI: 2.96-21.68] and [AOR=3.47, 95\%CI: 1.41-8.54]. Regarding to occupational status, daily laborers are two and 
half times more likely to establish informal settlements than government employs [AOR $=2.47,95 \% \mathrm{CI}$ : 1.08-5.66]. People whose age less than 30 years and found between 30-39 age categories were two and three times more likely to establish informal houses respectively than people with other age categories $[\mathrm{AOR}=2.42,95 \% \mathrm{CI}$ : 1.10-5.32] and [AOR $=2.78,95 \% \mathrm{CI}: 1.35-5.67]$.

Respondents who had less income were two and half times more likely to have chance of establishing informal houses than respondents who had more income $[\mathrm{AOR}=2.58$,
95\% CI: 1.57 - 4.23]. Regarding occupational status, daily laborers and house wives were more likely to establish informal houses than government employs respectively $[\mathrm{AOR}=2.47,95 \% \mathrm{CI}: 1.08-5.66]$ and $[\mathrm{AOR}=0.29,95 \% \mathrm{CI}$ : 0.11-0.78].

Sex, religion and ethnicity showed statistically significant difference in the crude analysis $[\mathrm{COR}=1.53,95 \% \mathrm{CI}$ : 1.05-2.24], [COR $=0.48,95 \% \mathrm{CI}: 0.25-0.92]$ and $[\mathrm{COR}=0.25$, 95\%CI: $0.07-0.84]$ respectively but, these associations did not retain their significance when adjusted for confounders.

Table 3. Factors associated with forms of settlement, 1 June - 31 September, 2011, Bahir Dar City, NW Ethiopia.

\begin{tabular}{|c|c|c|c|c|}
\hline \multirow[b]{2}{*}{ Variable } & \multicolumn{2}{|c|}{ Settlement form } & \multirow[b]{2}{*}{ COR $(95 \% C I)$} & \multirow[b]{2}{*}{ AOR (95\%CI) } \\
\hline & $\begin{array}{c}\text { Informal } \\
(n=185)\end{array}$ & $\begin{array}{c}\text { Formal } \\
(n=370)\end{array}$ & & \\
\hline \multicolumn{5}{|l|}{ Education status: } \\
\hline Illiterate & 55 & 50 & $11.73(5.36-25.68)^{*}$ & $9.28(3.24-26.57)^{*}$ \\
\hline Read and write & 31 & 45 & $7.35(3.23-16.72)^{*}$ & $5.58(1.95-15.96)^{*}$ \\
\hline Grade 1-6 & 43 & 41 & $11.19(4.50-25.05)^{*}$ & $8.02(2.96-21.68)^{*}$ \\
\hline Grade $7-8$ & 11 & 46 & $2.55(0.99-6.59)$ & $2.09(0.68-6.38)$ \\
\hline Grade 9-12 & 36 & 92 & $4.17(1.91-9.15)^{*}$ & $3.47(1.41-8.54)^{*}$ \\
\hline Certificate and above & 9 & 96 & 1.0 & 1.00 \\
\hline \multicolumn{5}{|l|}{ Age } \\
\hline$<30$ & 32 & 45 & $1.31(0.72-2.39)$ & $2.42(1.10-, 5.32)^{*}$ \\
\hline $30-39$ & 48 & 67 & $1.32(0.77-2.27)$ & $2.77(1.35-5.68)^{*}$ \\
\hline $40-49$ & 43 & 107 & $0.74(0.44-1.26)$ & $1.52(0.78-2.96)$ \\
\hline $50-59$ & 24 & 81 & $0.55(0.30-0.99)^{*}$ & $0.69(0.34-1.42)$ \\
\hline $60+$ & 38 & 70 & 1.0 & 1.0 \\
\hline \multicolumn{5}{|l|}{ Sex } \\
\hline Male & 121 & 275 & 1.0 & 1.0 \\
\hline Female & 64 & 95 & $1.53(1.05-2.24)^{*}$ & $0.81(0.46-1.43)$ \\
\hline \multicolumn{5}{|l|}{ Religion } \\
\hline Christian & 173 & 323 & 1.0 & 1.0 \\
\hline Muslim & 12 & 47 & $0.48(0.25-0.92)^{*}$ & $2.17(0.99-4.54)$ \\
\hline \multicolumn{5}{|l|}{ Occupation } \\
\hline Government Employee & 22 & 101 & 1.0 & 1.0 \\
\hline Merchant & 26 & 84 & $1.42(0.75-2.67)$ & $0.64(0.29-1.41)$ \\
\hline House Wife & 17 & 42 & $1.86(0.89-3.85)$ & $0.29(0.11-0.78)^{*}$ \\
\hline Daily laborer & 66 & 27 & $11.22(5.90-21.34)^{*}$ & $2.47(1.08-5.66)^{*}$ \\
\hline Farmer & 8 & 6 & $6.12(1.93-19.42)^{*}$ & $1.62(0.42-6.22)$ \\
\hline Others & 46 & 110 & $1.92(1.08-3.41)^{*}$ & $0.75(0.36-1.58)$ \\
\hline \multicolumn{5}{|l|}{ Monthly income } \\
\hline Less income & 124 & 61 & $4.08(2.80-5.94)^{*}$ & $2.58(1.57-4.23)^{*}$ \\
\hline More income & 123 & 146 & 1.0 & 1.0 \\
\hline \multicolumn{5}{|l|}{ Ethnicity } \\
\hline Amhara & 182 & 347 & 1.0 & 1.0 \\
\hline Others & 3 & 23 & $0.25(0.07-0.84)^{*}$ & $0.83(0.22-3.09)$ \\
\hline
\end{tabular}

* Indicates Significant Association

\section{Observation Results}

As expected, informally established housing units have much poorer housing conditions than formally established housing units whether we consider construction material, residential crowding, ventilation of the dwelling, practice of waste disposal or access to water and household sanitation facilities.

All the informal houses were built from simple Bamboo, woods and mud. They are overcrowded with lack of ventilation and lack of hygiene compared formally established houses. Informally established housing units lacked basic services such as access to safe water, paved walkways, drains, sanitation and other essential infrastructures compared to formally established houses.

Liquid and solid waste management were not safe in both forms of settlements. However, it was worst in informally established housing units. Informally built houses dispose kitchen and laundry grey water in roads and in front of the main gates. People practice open defecation. There are housing units without latrine facilities. Even existing latrines were poorly structured, unclean and lifeless. Accordingly, it was not uncommon to see human feces near their houses. Children were observed with barefooted and poorly dressed with unclean clothes on this unsafe living environment. They are places where alcoholic people, drug addicts and commercial sex workers were found. Sometimes the 
situation goes to the other extreme, where people abandon their homes, tempted by the prospect of unconsciousness through alcohol or drug abuse. Once people develop such problems the prospects of finding work may diminish. Accordingly, they fall deeper into poverty and the cycle continues.

Sexual abuses and gender based violence were frequently observed. Frequent border conflicts are also observed due to lack of boundary demarcations by municipality.

\section{Discussion}

The proportion of government employees among cases was $11.9 \%$ compared to 27.3 controls. This could be attributed to the fact that people in informal settlement are associated to low income groups. Accordingly, $67 \%$ of cases belong under low income category compared to $32.3 \%$ of controls. The implication of this is reflected in the daily standard of living as many are unable to meet their basic needs which make life more unbearable for them.

The study conducted in sub Saharan Africa showed that $40 \%$ of the urban housing is built from improper materials [3]. In this study, $74.1 \%$ of the housing units were built with low quality and non-durable materials. When we compare informal and formal housing units, all informally established houses were built with non-durable materials such as woods and mud, bamboo and plastics without or with poor structural quality which is by far less than a study done in Jamaica which shows that about $63 \%$ of informal established houses were constructed mainly from a combination of concrete and board [9]. Even the situation of houses in Bahir Dar is under poor condition compared to sub Saharan housing condition.

About $57.3 \%$ of informal houses had been built over 20 years ago compared to $30.8 \%$ of formally established houses. According to personal observation, most of the buildings were accessible by roads but, the main problem is that majority of the roads are not properly constructed and the conditions are extremely poor. The roads were characterized by poor drainage, lack of street lighting, absence of pedestrian walkway as well as on street parking.

The study revealed that $61.1 \%$ informal houses and $10 \%$ of formal houses had no any kind of kitchen. Even existing kitchen facilities were found in poor condition. About $18.9 \%$ of informal hadn't any kind of toilet facilities which is less compared to a study done in Jamaica which shows that only $3 \%$ of informally established housing units had no any kind of toilet facilities [9]. Majority of informal houses had no access to improved sanitation which is consistent with the study done in Zanzibar town in 2003 which indicates sanitation is the major problem in informal settlement areas due to the lack of established collection points, piles of garbage are scattered in and around residential areas which leads to environmental and health problems [10]. About $77.3 \%$ of informal houses have improper liquid waste management practice which is similar with a study done in Zanzibar in 2006 as there is no centralized sewage system, liquid waste which includes water from washing, laundry, kitchen, bath and other domestic uses is haphazardly discharged onsite. This disposal practice pollutes the groundwater and marine environments and is a major cause of water born diseases [1].

With regard to dry waste management, $50.8 \%$ of informal houses and $12.7 \%$ formal houses dispose inappropriate way.

Majority of the respondents (95.7\%) of informal houses and all formal houses had access to improved drinking water this finding is better than a study done in Jamaica which indicates that $85 \%$ of informal houses had improved drinking water [9].

Waste management deficiencies resulting in lack of drainage and uncontrolled solid and liquid waste disposal in the poor settlements lead to severe environmental health risks. The study conducted in selected six areas of Abidjan showed that the prevalence of disease mainly, malaria diarrhea and skin diseases in informal settlement had reported to be $48 \%$ [11]. Another study conducted in Dareselam, the capital of Tanzania found that cholera incidence was most closely associated with informal housing, population density, and the income level of informal residents [12].

A cross-sectional study was conducted in Yaoundé, the capital of Cameroon to measure diarrheal prevalence and identify factors associated with it. Lack of access to improved sanitation, existence of poor hygiene, overcrowding and uncomfortable housing found to be the risk factors for the prevalence of diarrhea. Accordingly, 16\% of the diarrhea prevalence was identified compared to $14.4 \%$ overall prevalence rate [13]. Concerning the prevalence of infectious disease in this study about $39.5 \%$ of informal houses and $10.8 \%$ of formally established houses were exposed to disease mainly malaria, typhoid, typhus and TB. This finding is lower than the findings of Abidjan and higher than the findings of Yaoundé study $[11,13]$.

\section{Conclusion and Recommendation}

This study was conducted on formally and informally established housing units to assess the situation of informal settlement in Bahir Dar City and reach at plausible conclusions. Accordingly, the conclusions were stipulated below: Informal settlement is associated with socio-economic and demographic factors such as respondents' age, educational status, occupation and average monthly income.

The prevalence of illness among informally established housing units were more than formally established housing units. Diarrheal diseases, malaria, typhoid and typhus were the most infectious diseases found to be prevalent in informally established housing units.

Based on the above findings and conclusions the investigators recommend the following points:-

- Keble small and Micro enterprises should work in expansions of income generation activities to create employment opportunities and generate more income. 
This can improve socioeconomic conditions of the people including access to shelter.

- The adverse effect of informal settlement on health status of the people should get the attention of health sector and remedial measures should be taken to minimize their negative impact.

\subsection{Strengthening and Limitations of the Study}

\subsubsection{Strengthening}

$\checkmark$ This study gives the increasing urbanization and population is an important step to generate information that could be useful to health policy makers and to planners.

$\checkmark$ There are no enough similar studies on urban informal settlement has been conducted in the country.

$\checkmark$ The study design being case - control enabled to generate more information on the associated factors.

\subsubsection{Limitations}

$\checkmark$ Lack of similar studies hindered further comparison of the results

$\checkmark$ Some respondents may not give exact information assuming that the result of the study may affect them

\section{Acknowledgements}

The authors acknowledge data collectors and participants for their willingness to participate and spent their precious time for the success of the study. The authors also thank Bahir Dar Metropolitan City Administration for its full-fledged support during the study period. Finally we are grateful for Wzo Abebu Jemberie and Wzo Yeshi Abebe for their financial support in conducting this study

\section{Computing Interests}

The authors declared that they have no any computing interests

\section{References}

[1] Alim M. Sulaiman S. The causes and Consequences of the Informal Settlements in Zanzibar Tanzania. October $8-13$, 2006.
[2] Aik W. Anger A. Reis G. Slum health; Diseases of neglected populations. BMC International Health and Human Rights. 2007;7:2 available from: URL: http://www.biomedcentral.com/1472-698X/7/2

[3] Napier M. Informal settlement integration, the environment and sustainable livelihoods in sub-Saharan Africa. March 2005. Available from: URL: www.grif.umontreal.ca/pages/i-rec\%20papers/napie.

[4] Santosa H. Environmental hazards management in informal settlements to achieve sustainable livelihoods of the poor. The case of East Java - Indonesia. 2003. Available from: URL: www.ipt.co.in/2013/april/Drainage\%20\&\%20Stormwater.

[5] Bahir Dar metropolitan city Administration. Bahir Dar integrated development plan from 2006/2007 to 2010/2011. Bahir Dar, Ethiopia.

[6] HABITAT. Slums of the World; The face of urban poverty in the new millennium. Nairobi: UN Habitat 2003.

[7] Central Statistical Agency [Ethiopia]. ORC Macro, Ethiopian demographic and health survey 2005. Addis Ababa, Ethiopia. Calverton, Maryland, USA, 2006.

[8] WHO. Access to improved drinking-water sources and to improved sanitation. WHO Statistical Information System (WHOSIS), 2008.

[9] Ministry of water and housing. Rapid assessment of the status of squatting settlements. Jamaica, 2008. Available from URL: www.mwh.gov.jm/new/.../Rapid_Assessment_of_Squatting Report.pdf.

[10] Ameyibor R. Informal settlements development on Zanzibar; A study on the community based provision of storm water management. University of Dortmund; Germany, 2003.

[11] Dongo K. Zurbreg C. Cissel G. etal. Environmental Risks and Perceptions of Risks to Assess Health and Well-being in Poor Areas of Abidjan. International Journal of Civil and Environmental Engineering 2:4; 2010.

[12] Penrose K. Castro M Cd. Werema J. Ryan ET. Informal urban settlements and cholera risk in Dares Salaam, Tanzania. PLoS neglected tropical diseases. March 2010; 4(3): Available from: e631. doi:10.1371/journal.pntd.0000631.

[13] Yongsi H. Human settlement, land management and health in Sub Saharan cities. International journal of human and social sciences. 2009;4(1). 